\title{
BERBAGI BUKU, BERBAGI ILMU UNPAD 2013: KONTRIBUSI UNIVERSITAS PADJADJARAN DALAM PEMBINAAN MINAT BACA MASYARAKAT PROVINSI JAWA BARAT MELALUI PEMBERDAYAAN PERPUSTAKAAN DAN TAMAN BACAAN MASYARAKAT
}

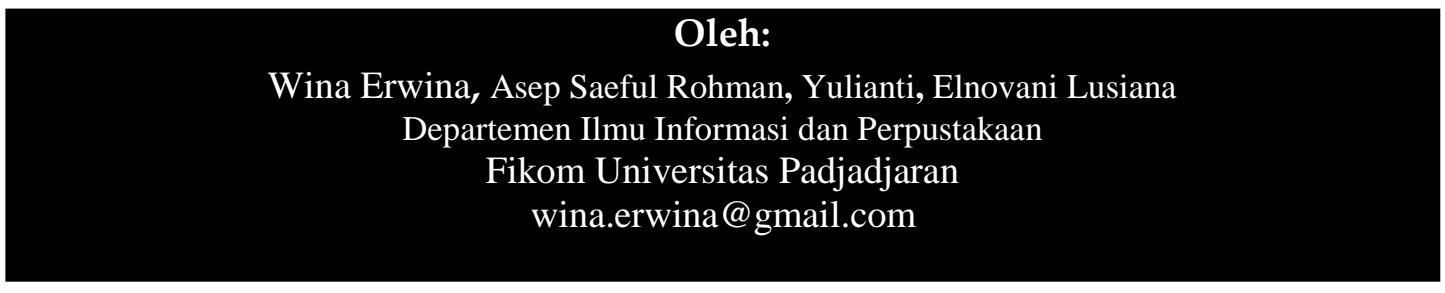

\begin{abstract}
The present study investigated applicability of Pustaka Access versi 0.1 designed by fakulty members of Padjadjaran University (Unpad). Being the aim of the software application was an effort to make reading interest of the west java people geared to wards betterments. At present, libraries scaterred across the province of west java are not managed by professional librarians. By way applying the software of pustaka access versi 0.1 developed though database Microsoft access 2007 (or, the most recent version of it) The best part of the software application proves to be some practicality and accuracy in term of benefiting the library collection from which people learn how to live a better life in a broader sense.Libraries of different kinds include Taman Bacaan Masyarakat (TBM), library-like center of resources for all people including those living villages in rural areas. These libraries are to be managed by librarians having been trained through services workshops on electronic system of running a library for all.
\end{abstract}

Keyword: TBM, reading interest, Unpad, software

\begin{abstract}
ABSTRAK
Provinsi Jawa Barat merupakan provinsi yang memiliki angka buta aksara mencapai angka 10 \%. Indeks Pembangunan Manusia (IPM) di Jawa Barat terus ditingkatkan. Berbagai program dicanangkan untuk mendongkrak angka IPM tersebut agar menjadi lebih baik. Salah satu indikator yang diperhatikan adalah peningkatan minat baca masyarakat. Sumber inspirasi kegiatan ini adalah bahwa perpustakaan Desa dan TBM (Taman Bacaan Masyarakat) di Jawa Barat belum memiliki solusi praktis mengatasi masalah dalam mengembangkan perpustakaan/TBM yang mereka kelola. Belum ada kesiapan dalam menyelenggarakan layanan perpustakaan/TBM berbasis sistem. perpustakaan/TBM masih memerlukan tambahan bahan bacaan. Pihak pengelola belum memiliki Tenaga Teknis yang siap mengelola koleksi bahan bacaan. Metode yang dilakukan adalah Survey Kebutuhan Informasi, Pendidikan dan Pelatihan , Konsultasi dan Focus Group Discussion (FDG) serta simulasi Ipteks, yakni diperkenalkan kepada para pengelola taman bacaan masyarakat dan perpustakaan desa adalah Sofware
\end{abstract}


Pustaka Access Versi 0.1. Software ini dimanfaatkan untuk pengolahan koleksi bahan pustaka dengan mengunakan software Pustaka Acces Versi 0.1 yang digagas dan dikembangkan oleh staf pengajar pada Departemen Ilmu Informasi dan perpustakaan Fakultas Ilmu Komunikasi Unpad. Karya Utama kegiatan ini adalah berupa Software Pustaka Acces Versi 0.1, Modul Pengolahan Koleksi, Modul Perpustakaan Sekolah dan Modul Pengelolaan Taman Bacaan Masyarakat. Software "Pustaka Access versi 0.1" dikembangkan dengan menggunakan Database Microsoft Access 2007.Oleh karena itu, Software ini hanya bisa digunakan pada komputer yang sudah terinstal Microsoft Office 2007 (atau Microsoft Office versi yang lebih baru). Modul pengolahan koleksi merupakan pedoman yang dapat digunakan dalam mengoperasikan system pengolahan koleksi berbasis elektronik. Modul perpustakaan sekolah, dapat digunakan bagi sekolah dalam menjalankan pengelolaan perpustakaan sekolahnya secara ringkas dan cepat. Modul Pengelolaan Taman Bacaan Masyarakat dapat digunakan oleh Taman Bacaan Masyarakat sebagai panduan pengelolaan dan pengembangan Taman Bacaan Masyarakat. Dampak dan manfaatnya adalah bahwa pemberian hibah buku yang siap dipakai memudahkan pengelola perpustakaan dan taman bacaan untuk dapat langsung dimanfaatkan oleh pemustakanya. Pelatihan sistem pengelolaan elektronik memudahkan pengelola dalam mengurus koleksinya. Hal ini disampaikan oleh pengelola yang telah mendapat pelatihan, dan antusias pemustakanya untuk bisa segera meminjam buku tersebut. Kesimpulan bahwa kegiatan Hibah buku mahasiswa angkatan 2013-2014 telah tersampaikan ke berbagai jenis perpustakaan dan taman bacaan baik itu perpustakaan sekolah, taman bacaan masyarakat dan perpustakaan Lapas. Diberikan kepada sekolah yang belum memiliki perpustakaan dan sekolah yang belum memenuhi standar jumlah koleksi. Taman bacaan yang mendapat hibah adalah taman bacaan yang memulai dan mengembangkan dengan motivasi yang kuat dari pengelolanya. Permasalahan cara pengelolaan terbantukan dengan pelatihan dan pemberian sistem pengelolaan elektronik. Koleksi yang telah terolah mempercepat layanan bagi pemustaka untuk memanfaatkannya.

Kata kunci: Taman Bacaan Masyarakat, Minat Baca, Pemberdayaan perpustakaan, Unpad 


\section{A. Pendahuluan}

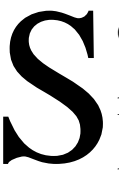

etelah 68 tahun Indonesia merdeka, angka buta aksara masyarakat Indonesia masih belum memberikan kabar yang membahagiakan. Jumlah angka buta hufuf pada masyarakat di Indonesia adalah 8,5 juta jiwa dan 5,1 juta jiwa diantaranya adalah Perempuan. Angka tersebut sudah mengalami penurunan jika dibandingkan dengan tahun 2004 yang menunjukkan 15 juta dari penduduk Indonesia buta huruf. Angka buta huruf ini masih merupakan angka terbesar di dunia (Nahaba 2013).

Pada tahun 2012 Masyarakat dengan usia produktif dengan rentang 15 - 59 tahun, terdapat 3,6 juta jiwa yang masih buta aksara hal ini disampaikan oleh Pria Gunawan Kepala Balai Pengembangan Anak Usia Dini Pendidikan Nonformal dan Informal Kementrian Pendidikan. Selanjutnya, presentase nasional ketunaaksaraanmasyarakat Indonesia dengan usia 15-59 tahun ini berdasarkan sensus penduduk pada tahun 2010 mencapai 5,02 \% dari jumlah penduduk Indonesia yang buta huruf yakni 7,5 juta jiwa (Ucu 2013).

Berdasarkan fenomena yang terdapat pada masyarakat Indonesia mengenai buta aksara memang cukup memprihatinkan. Pasalnya laju pertumbuhan ekonomi masyarakat Indonesia belum diiringi dengan pekembangan dalam bidang pendidikan khususnya membaca. Hal tersebut terlihat dari masih terdapat provinsiprovinsi di Indonesia yang memiliki angka buta huruf lebih dari $10 \%$. Provinsi dengan tingkat buta huruf diatas $10 \%$ diantaranya Papua, Nusa Tenggara Timur, Nusa Tenggara Barat, Sulawesi Selatan dan Jawa Barat (Nahaba 2013). Daerah terpencil di pedesaan, pemukiman kumuh dan padat penduduk di perkotaan disinyalir menjadi kantong-kantong yang berkotribusi terhadap besaran angka buta aksara pada masyarakat di Indonesia.

Berdasarkan survey di lapangan menunjukkan masyarakat di Indonesia tidak suka membaca, hasil suvery minat baca orang Indonesia hanya 0,001 \% atau satu berbanding 1.000 orang (Ainan 2013). Perpustakaan dan taman bacaan masyarakat merupakan salah satu wadah yang menjadi motor pengerak dalam pemberantasan buta aksara pada masyarakat di Indonesia. Keseriusan 
pemerintah dalam meningkatkan indeks pembangunan melalui perpustakaan sudah terlihat dengan dirumuskannya Undang-Undang Republik Indonesia Nomor 43 Tahun 2007 tentang Perpustakaan.

Provinsi Jawa Barat merupakan salah satu dari sepuluh provinsi yang memiliki angka buta aksara mencapai angk $10 \%$. Melihat demografi Jawa Barat bukanlah daerah yang terpencil yang memiliki keterbatasan akses terhadap informasi. Berbagai universitas dan sekolah tinggi berdiri di Jawa Barat yang menghasilkan ribuan sarja setiap tahunnya.

Untuk itu, Indeks Pembangunan Manusia (IPM) di Jawa Barat terus ditingkatkan. Berbagai program pun dicanangkan untuk mendongkrak angka IPM tersebut agar menjadi lebih baik lagi. Bagaimanapun angka tersebut akan menunjukkan kualitas pembangunan di Jawa Barat. Salah satu indikator yang diperhatikan adalah peningkatan minat baca masyarakat, dengan ini diharapkan adanya penurunan angka buta huruf, kemiskinan dan pengangguran.

Keterbatasan, merupakan sebuah alasan klasik dari tahun ke tahun yang tak kunjung terselesaikan. Minimnya fasilitas, bahan bacaan, dan keterbatasan akses masyarakat di daerah pelosok terdahap sumber-sumber informasi sepertinya terus menjadi alasan klasik disetiap tahunnya. Permasalahan ini bukan hanya permasalahan bagi pemerintah saja, namun menjadi permaslahan bagi institusi pendidikan yang sekaligus memiliki tangung jawab yang besar dalam mewujudkan cita-cita bangsa Indonesia yang tertuang dalam pembukaan Undang-Undang Dasar 1945 yaitu mencerdaskan kehidupan bangsa.

Melihat keberadaan universitas yang terdapat di Provinsi Jawa Barat, tentu dapat bekerjasama dengan pemerintah setempat dan sudah barang tentu hal ini menjadi tanggung jawab moral dari sebuah universitas untuk mengabdi kepada masyarakat setempat dimana universitas tersebut berada.

Sama halnya dengan perusahaanperusahaan yang beraktivitas suatu wilayah, tentu turut serta bertangung jawab dalam indeks pembangunan masyarakat. Jika sebuah perusahaan dikenal dengan Corporate Social Responsibility (CSR) yang merupakan salah satu bentuk tangung jawab sebuah perusahaan dalam mendukung berbagai 
kegiatan masyarakat sekitar untuk meningkatkan taraf kehidupan kearah lebih baik, maka perguruan tinggu sebagai institusi pendidikan juga memiliki tanggung jawab yang sama.

Perguruan tinggi sebagai institusi pendidikan tentu memiliki tanggung jawab yang tak kalah penting untuk mewujudkan kehidupan masyarakat kearah yang lebih baik. Tri Dharma Perguruan Tinggi, sudah mengatur aktivitas yang dilakukan oleh sebuah perguruan tinggi, yaitu pendidikan, penelitian dan pengabdian kepada masyarakat. Hal ini menunjukkan bahwa peguruan tinggi bukanlah sebuah lembaga yang melakukan kegiatan pendidikan semata, namun juga terdapat penelitian dan pengabdian kepada masyarakat.

Keberdayaan Unpad sebagai institusi pendidikan di Jawa Barat tentu diharapkan dapat memberikan kontribusi dalam peningkatan indeks pembangunan masyarakat Jawa Barat ke arah yang lebih baik. Turut berkontribusi besar terhadap peningkatan taraf hidup masyarakat Jawa Barat kearah yang lebih baik. Sebagai wujud pengabdian Unpad dalam percepatan pemberantasan buta huruf, dan mewujudkan masyarakat informasi sudah dimulai semenjak Unpad berdiri di Jawa Barat.

Universitas Padjadjaran juga menunjukkan komitmen yang penuh dalam peningkatan indeks pembangunan masyarakat melalui pemberantasan buta aksara. Upaya Unpad sebagai universitas di provinsi Jawa Barat sudah terlihat semenjak tahun 2008 dengan menyediakan sumber daya fisik untuk perpustakaan dan taman bacaan masyarakat dalam bentuk bahan bacaan dan koleksi untuk perpustakaan.

Berbagi buku, berbagi ilmu merupakan program hibah buku yang digagas oleh Unpad sebagai wujud pengabdian kepada masyarakat Provinsi Jawa Barat. "Unpad Nyaah ka Jabar" Program Hibah ini terwujud berkat dukungan dari civitas akademika Universitas Padjadajran melalui sumbagan buku yang dihimpun dari mahasiswa baru tahun akademik 2009/2010 dengan jumlah sebanyak 7.000 eksemplar buku. Sumbagan mahasiswa ini diteruskan pada masyarakat Tasikmalaya yang diserahkan lansung melalui Pemerintah Daerah Kabupaten Tasikamalaya. Program hibah buku disetiap tahun 
akademik ini terus berlangsung dan terus bergulir ke beberapa daerah lainnya di Jawa Barat. Program Hibah Buku yang dinahkodai Lembaga Penelitian dan Pengabdian Kepada Masyarakat Universitas Padjadjaran (Unpad 2010).

Selanjutnya, pada tahun 2013 ini kebutuhan masyarakat tidak lagi sebatas sumber daya fisik koleksi saja, akan tetapi pembinaan terhadap pada pengelola perpustakaan desa, sekolah dan taman bacaan masyarakat juga perlu dilakukan. Program yang unuk mengelola sumber daya koleksi tersebut juga menjadi fokus perhatian oleh Departemen Ilmu Informasi dan Perpustakaan Universitas Padjadjaran.

Dengan demikian, pada tahun 2013 ini Lembaga Penelitian dan Pengabdian Kepada Masyarakat Unpad mengandeng Departemen Ilmu Informasi dan Perpustakaan Fikom Unpad untuk melalukan survey kebutuhan taman bacaan masyarakat dan perpustakaan yang akan menjadi mitra kegiatan. Hal tersebut dilakukan agar koleksi yang disalurkan benarbenar sesuai dengan kebutuhan informasi masyarakat dan disesuaikan dengan kondisi georgafi dan demografi masyarakat setempat. Disamping itu, pelatihan pengelolaan perpustakaan juga dilakukan agar lembaga informasi tersebut memiliki daya guna bagi masyarakat setempat.

\section{B. Perpustakaan dan TBM}

Perpustakaan Desa dan TBM (Taman Bacaan Masyarakat) di Wilayah Provinsi Jawa Barat belum memiliki solusi praktis yang dapat ditempuh untuk mengatasi masalah dan persoalan dalam mengembangkan perpustakaan maupun TBM yang mereka kelola. Bangunan, ruangan, koleksi bahan bacaan dan peralatan pendukung lainnya sudah cukup memadai. Namun yang masih menjadi masalah utama adalah belum adanya kesiapan dalam menyelenggarakan layanan perpustakaan/TBM berbasis sistem. Selain itu, mereka masih memerlukan tambahan bahan bacaan. Pihak pengelola belum memiliki Tenaga Teknis atau Sukarelawan yang siap dan memiliki kemampuan dalam mengolah dan mengelola koleksi bahan bacaan.

$$
\text { Pengelolaan koleksi di }
$$
perpustakaan dan taman bacaan masyarakat merupakan kebutuhan yang mendesak. Hal ini dilatarbelakangi 
sudah mulai berkembangnya taman bacaan masyarakat dan perpustakaanperpustakaan desa di Jawa Barat, namun pengelolaan dan pemberdayaan koleksi dari taman bacaan masyarakat serta perpustakaan desa tersebut belumlah efektif.

Minimnya masyarakat terhadap pemberdayaan koleksi, manajemen koleksi yang terdapat di taman bacaan masyarakat dan perpustakaan desa dari sisi keilmuan merupakan permasalahan yang cukup penting, agar koleksi yang telah didistribusikan oleh Universitas Padjadjaran tersebut dapat diberdayakan sebagai pusat pembelajaran alternatif bagi masyarakat.

Kebutuhan masyarakat terhadap pembinaan tersebut dilihat dari beberapa surat masuk yang dikirim oleh perpustakaan desa dan taman bacaan masyarakat kepada Universitas Padjadjaran melalui Departemen Ilmu Informasi dan Perpustakaan yang bernaung di bawah Fakultas Ilmu Komunikasi. Disamping itu, para pengelola perpustakaan dan taman bacaan masyarakat juga ingin meningkatkan kapasitas dalam pengelolaan perpustakaan. Sehingga para pengelola perpustakaan dan taman bacaan masayarakat berkeingginan untuk mendapatkan pembinaan langsung dari Departemen Ilmu Informasi dan perpustakaan, karena Departemen ini telah menghasilkan para professional yang memiliki kompetensi utama dalam pengelolaan informasi yang berbasiskan pada teknologi informasi.

Berbagai bidang kepakaran yang dimiliki oleh tenaga ahli dalam bidang ilmu informasi dan perpustakaan diharapkan dapat berkontribusi besar dalam meningkatkan kemampuan masyarakat di daerah untuk memberdayakan perpustakaan desa dan taman bacaan masyarakat sebagai sumber informasi terdekat yang berada di tengah-tengah masyarakat.

Permintaan masyarakat dari berbagai daerah di Jawa Barat terhadap pengadaan koleksi dan pemberdayaanya pada Departemen Ilmu Informasi dan Perpustakaan telah diteruskan kepada pimpinan Universitas Padajadjaran. Hal tersebut ditindaklanjuti oleh Universitas Padjadjaran pada tahun akademik 2013/3014 ini mengandeng Departemen Ilmu Informasi dan Perpustakaan untuk mendukung sepenuhnya Program Hibah 
EduLib, Vol 1, No.2 November 2014

Buku yang telah diinisiasi oleh Lembaga Penelitian dan Pengabdian Kepada Masyarakat (LPPM) Universitas Padjadjaran ditahun-tahun sebelumnya.

Komitmen penuh Departemen Ilmu Informasi dan Perpustakaan ini mengusung konsep community development dengan tujuan untuk mewujudkan masyarakat yang literate melalui penyediaan bahan-bahan bacaan yang tepat sesuai dengan kebutuhan masyarakat dan membantu masyarakat agar dapat mengelola taman bacaan masyarakat dan perpustakaan desa sebagai pusat informasi dan pembelajaran yang terdekat di masyarakat, secara mandiri. Menuju ke arah information society demi mewujudkan long life learning. Hal tersebut bertujuan agar taman bacaan masyarakat dan perpustakaan desa berperan terhadap pendidikan masyarakat setempat meskipun dilakukan melalui program pendidikan informal.

Pendekatan yang dilakukan untuk menentukan metode apa yang dapat dilaksanakan dalam menyelesaikan persoalan mitra yakni dengan cara berikut :

1. Survey Kebutuhan Informasi

Hal ini dilakukan untuk melihat informasi apa yang dibutuhkan masyarakat yang akan menjadi titik penyaluran koleksi nantinya. Melalui survey tersbut akan telihat jenis-jenis koleksi yang menjadi prioritas kebutuhan masyarakat setempat.

Disamping itu, melalui survey ini juga dilakukan koordinasi dengan para pengelola perpustakaan desa maupun TBM yang tergabung dalam komunitas KABACA. Diharapkan dengan koordinasi ini baik Tim maupun target sasaran memiliki kesiapan dari masing-masing target sasaran kegiatan PKM ini untuk mengikuti secara intensif program dan kegiatan yang akan dilaksanakan bersama. Termasuk penentuan waktu pelaksanaan sesuai kesepakatan, tempat lokasi pelaksanaan berbagai kegiatan yang akan dilaksanakan dan kepanitiaan teknis yang akan membantu kelancaran keseluruhan Program Kegiatan PKM.

2. Pendidikan dan Pelatihan Dalam kegiatan ini Departemen Ilmu Informasi dan Perpustakaan melalukan pembinaan kepada para penggelola perpustakaan sekolah, perpustakaan Lapas, perpustakan desa dan taman bacaan masyarakat dengan memberikan materi pendidikan dan pelatihan. Pelatihan diberikan yaitu Pengenalan Anatomi Buku, Pengolahan Koleksi teknik klasifikasi, teknik kata logisasi berbasis sistem otomasi dan 
Strategi Pemberdayaan Minat Baca Masyarakat.

3. Konsultasi dan Focus Group Discussion (FDG).

Konsultasi dan Focus Group Discussion ini dilakukan untuk melihat persoalan-persoalan yang terdapat pada setiap perpustakaan dan taman bacaan masyarakat. Melalui FGD ini dapat diketahui prioritas utama mitra kegiatan dalam pengelolaan taman bacaan masyarakat dan perpustakaan. FGD ini difasilitatori oleh para staf pengajar Departemen Ilmu Informasi dan Perpustakaan dengan mendiskusikan isu-isu mengenai pengelolaan perpustakaan sekolah, perpustakaan desa, dan taman bacaan masyarakat.

4. Simulasi Ipteks

Simulasi Ilmu pengetahuan dan teknologi yang diperkenalkan kepada para pengelola taman bacaan masyarakat dan perpustakaan desa adalah Software Pustaka Access Versi 0.1. Software ini dimanfaatkan untuk pengolahan koleksi bahan pustaka dengan mengunakan software Pustaka Acces Versi 0.1 yang digagas dan dikembangkan oleh staf penganjar di Departemen Ilmu Informasi dan perpustakaan Fakultas Ilmu Komunikasi.

5. Pengolahan Koleksi

Koleksi yang akan disalurkan ke taman bacaan masyarakat dan perpustakaan sebelumnya telah diolah yaitu terkait dengan pelabelan nomor panggil buku (call number), klasifikasi buku, entri data base. Diawali dengan pemilihan koleksi yang sesuai dengan

pemustakanya/

pembacanya.

Dalam kegiatan pengolahan koleksi ini melibatkan mahasiswa Departemen Ilmu Informasi dan Perpustakaan serta bekerja sama dengan Laboratorium Pengolahan Informasi di Fakultas Ilmu Komunikasi dan Fikom Library and Knowledge Center.

Penyaluran koleksi dilakukan dengan menyerahkan koleksi sebanyak 250 hingga 500 eksemplar pada setiap titik. Tim menyarahkan koleksi yang sudah diseleksi sesuai dengan kebutuhan informasi perpustakaan tersebut. Di samping itu, setiap mitra kegiatan juga memperoleh satu paket modul pengelolaan koleksi, $\mathrm{x}$-banner nama perpustakaan/taman bacaan, software Pustaka Acces Versi 0.1 dan data base koleksi yang diserakah.

Dalam pengolahan koleksi bahan pustaka/buku beberapa tahapan yang dilakukan adalah sebagai berikut ini.

a. Inventarisasi Pada Buku Induk

Kegiatan inventarisasi bahan pustaka merupakan kegitan yang dilakukan oleh petugas perpustakaan bagian pengolahan dengan cara memasukkan perolehan buku ke 
dalam buku induk. Selanjutnya buku yang diperoleh perpustakaan diawali dengan pemberian nomor urut satu dan seterusnya. Pemberian nomor urut di buku induk dapat dilakukan dengan cara terus menerus dan tidak berganti tiap tahunnya, itu cara yang pertama. Cara yang kedua pemberian nomor diawali nomor satu setiap tahunnya. Kedua sistem ini samasama ada kegunaannya, apabila menggunakan system yang pertama apabila ingin mengetahui jumlah koleksi yang dimiliki oleh perpustakaan.

b. Pemberian Stempel Buku

Semua buku yang masuk ke perpustakaan di bagian unit pengolahan sebelum dimasukkan dalam buku induk sebaiknya dibubuhkan stempel inventarisasi dahulu. Cara pemberian stempel pada umumnya pada lembar kedua dari judul diberi stempel inventaris yang memuat kode buku, no. register buku, tanggal penerimaan buku serta jumlah buku. Stempel milik perpustakaan ini ada hubungan dengan pengamanan buku. Oleh karena itu pembubuhan stempel milik perpustakaan bisa dibubuhkan pada halaman tertentu tidak diketahui oleh orang lain atau pengunjung perpustakaan.

c. Klasifikasi Bahan Pustaka

Klasifikasi bahan pustaka dilakukan untuk menghimpun dan mengelompokkan buku perpustakan yang memiliki subyek yang sama. Hal ini dilakukan untuk memudahkan penelusuran kembali bahan pustaka tersebut jika dibutuhkan. Dalam pengolahan buku (processing), klasifikasi merupakan salah satu bagian pekerjaan teknis yang penting.

d. Katalogisasi (entrie data-base)

Katalog merupakan deskripsi dari sebuah koleksi. Pada katalog terdapat informasi-informasi yang berisikan mengenai penting yang dapat mendeskripkan koleksi perpustakaan. Dalam hal ini pengolahan koleksi telah didukung oleh Pustaka Acces Versi 0.1 dan para mahasiswa yang terlihat dalam pengolahan koleksi mengentrikan data yang terkait dengan informasi koleksi.

Berikut ini sumber informasi yang di input kedalam sistem Pustaka Access Versi 0.1, beserta sumber perolehan informasinya. 
- Judul

Merupakan informasi yang terkait dengan Judul dari sebuah koleksi, informasi ini dapat diperoleh pada halaman judul.

- Pengarang

Pengarang merupakan orang yang bertangung jawab terhadap isi buku tersebut. Pengarang dapat berupa perseorangan, kelompok atau badan koorporasi. Disamping itu yang dapat dientrikan pada bagian kepengarangan ini adalah penerjemah, penyunting dan editor. Informasi mengenai hal tersebut terdapat pada halaman balik judul.

- Edisi

Memberikan informasi mengenai edisi dari koleksi tersebut, informasi ini terdapat pada halaman judul utama dan balik judul.

- Impresum

Ini berkaitan dengan informasi mengenai penerbitan, yaitu penerbit dan kota terbit. Informasi mengenai hal ini terdapat pada halama judul dan halam balik judul.

- Kolasi

Kolasi merupakan gambaran mengenai deskripsi fisik buku, meliputi jumlah halaman, tinggi dan lebarnya sebuah buku.

- ISBN

International Standard Book Number merupakan nomor indentifikasi buku secara internasional. Nomor ini terdapat apda halaman balik judul atau halaman sampul belakang buku.
Buku sumbangan Unpad pada tahun 2013 yang diolah di Laboratorium Pengolahan Informasi Fikom Unpad sebanyak 17.000 eksemplar.

6. Penyaluran Koleksi

Koleksi diserahkan pada 25 titik perpustakaan desa, perpustakan sekolah, perpustakaan Lapas dan taman bacaan masyarakat. Lokasi penyerahan tersebut berada pada wilayah provinsi Jawa Barat. Para penglola dan pimpinan sekolah diundang untuk mengikuti pelatihan pengelolaan perpustakaan.

Berikut adalah titik-titik mitra yang menjadi sasaran penyerahan buku dan pembinaan dalam program ini, yakni:

\section{Kab. Sumedang}

Perpustakaan SDN Cikuda

Perpustakaan SDN Neglasari

Perpustakaan SDN Cikeruh 2

SMAN Jatinangor

SMPN 1 Jatinangor

SDN Hegarmanah 1

Perpustakaan Desa Cilayung

Perpustakaan Desa Citali

Kab. Bandung

TBM Sudut Baca Soreang

TBM Edu Corner

SDN 2 Ganjar Sabar Nagreg

SDN Pasirhuni

TBM Pesantren Daarul Fatwa

Perpustakaan SDN Cijagra

TBM RW.09 Bojongsoang

Perpustakaan SDN Cigembar

\section{Kab. Garut}

Mts Sunan Cipancar 
Kab. Tasikmalaya

TBM BSP Sindangkerta

TBM Cigalontang

SDN Sindangkerta

Kota Bandung

TBM Desa Kertasari

Bandung

Perpustakaan LAPAS Wanita

TBM Sanggar Waringin

SMPN 2 Bandung

SMPN 30 Bandung

Total keseluruhan dari perpustakaan dan taman bacaan yang menjadi binaan Universitas Pajadjaran tahun 2013 ini adalah sebanyak 25 titik.

\section{Karya Utama}

Adapun yang menjadi karya utama yang dihasilkan dari kegiatan pengabdian kepada masyarakat ini adalah sebagai berikut.

- Pustaka Access Versi 0.1

- Untuk pengelolaan perpustakaan dengan basis sistem otomasi perpustakaan.

- Modul pengolahan koleksi bahan pustaka monograf dengan mengunakan sistem otomasi perpustakaan.

- Modul pengelolaan perpsutakaan sekolah

- Modul pengelolaan taman bacaaan masyarakat.

\section{Ulasan Karya}

- Pustaka Access Versi 0.1

Pustaka Access Versi 0.1 ini dikembangkan oleh Kunandar, M.Si

Staff pengajar di Departemen Ilmu Informasi dan Perpustakaaan Fakultas Ilmu Komunikasi Universitas

Padjadjaran.

Sofraware pustaka Access Versi 0.1 ini dikembangkan dengan mengunakan database dengan basis Microsoft Access 2007. Pada awalnya software ini diciptakan untuk kebutuhan pengelolaan perpustakaan yang sanggat sederhana, karena software ini bersifat off-line. Sehingga untuk menjalankanya tidak membutuhkan jaringan internet yang cepat.

Untuk mendukung kegiatan operasional pada sebuah perpustakaan tentu dibutuhkan sebuah manajeme yang baik, teknologi informasi merupakan salah satu alat yang dapat digunakan untuk melakukan hal tersebut. Untuk menjalankan software Pustaka Access Versi 0.1 ini cukup membutuhkan satu unit PC (personal computer) yang didukung ndengan aplikasi Microsoft Access 2007. Oleh karena itu, Software ini hanya bisa digunakan pada komputer yang sudah terinstal Microsoft Office 2007 (atau Microsoft Office versi yang lebih baru).

Konsep one to many merupakan 
salah satu konsep yang dapat diterapkan dalam sistem otomasi perpustakaan yang didukung oleh teknologi informasi. Beberapa kegiatan operasional perpustakan yang dapat dibantu melalui pengunaan software ini, dengan cukup mengentrie data hanya satu kali setiap judul dapat menghasilkan output sebagai berikut ini:

1. Data Koleksi Buku,

2. Input Data Koleksi Buku,

3. Print Katalog Semua Buku.

4. Print Katalog Satu Buku,.

5. Print Label Semua Buku,

6. Print Label Satu Buku,

7. Print Label Kartu Semua Buku,.

8. Print Label Kartu Satu Buku,

9. Print Label Kantong Semua Buku,

10. Print Label Kantong Satu Buku,

Keunggulan yang dimiliki oleh software ini adalah mudah untuk dipahami dan dioperasional bagai para petugas perpustakaan sekolah dan taman bacaan masayarakat. Namun, kemampuan dalam mengoperasionalkan komputer tentu dituntut untuk menjalankan software Pustaka Access Versi 0.1 ini.

Untuk melengkapi dan mendampinggi para mitra kegiatan yang sudah memperoleh satu software setiap perpustakaan dan TBM, maka pengembang dan tim memberikan sebuah modul mengenai teknik pengunaan software dan pengolahan bahan pustaka dalam bentuk buku.

Dalam pengembangan software ini terdapat beberapa kendala yaitu, untuk menciptakan software yang mudah dipahami oleh para pengelola perpustakaan dan taman bacaan walaupun mereka tidak berlatar belakang pendidikan ilmu informasi dan perpustakaan dibutuhkan bahasa pemrograman yang baik. Hal ini disebabkan maduakan kemampuan pengelolaan perpustakaan secara manual dengan sistem data base yang diintegrasikan dalam sebuah aplikasi. 


\section{PUSTAKA AGGESS versi 0.1}

Data Koleksi Buku

Input Data Koleksi Buku

MATALOR BUKU

Print Katalog Semua Buku

Print Katalog Satu Buku

IABEL BUKU

[1] Print Label Semua Buku

Print Label Satu Buku

\section{MBEL KARTU BUKO}

[ Print Label Kartu Semua Buku

Print Label Kartu Satu Buku

\section{IABEL KANTONG BUKO}

Print Label Kantong Semua Buku

Print Label Kantong Satu Buku

( 2 eluar Program

\section{Gambar 1}

Menu Utama Pustaka Access Versi 0.1

- Modul Pengolahan Koleksi Monograf dengan mengunakan sistem otomasi perpustakaan.

Pada modul ini dijelaskan mengenai anatomi dari koleksi monograf, yaitu anatomi buku. Modul ini disusun agar para pengelola perpustakaan desa, perpustakaan sekolah dan tamaan bacaan masyarakat dapat mengolah koleksi perpustakaan secara mandiri dengan mengunakan sistem dan aplikasi yang sudah diserahkan oleh Universitas Padjadjaran.

- Modul Perpustakaan Sekolah Pada modul ini dijelaskan mengenai manajemen dan sistem operasional perpustakaan sekolah. Disamping itu, modul ini juga berisikan ringkasmengenai penjelasan pengelolaan perpustakaan sekolah.
- Modul Pengelolaan Taman Bacaan Masayarakat.

Modul ini berisikan mengenai panduan yang dapat digunakan secara praktis oleh para pengelola taman bacaan masyarakat dalam mengelola sumber daya koleksi di taman bacaan serta upaya yang dapat dilakukan untuk pengembangan taman bacaan dimasa yang akan datang.

\section{Dampak dan Manfaat Kegiatan}

Program Hibuah Buku yang diselengarakan oleh Universitas Padjadjaran melalui PKM ini dapat memberikan beberapa dampak dan manfaat bagi para pengelolaa psrpustakaan sekolah, desa dan taman 
bacaan masyarakat. Adapun manfaat yang diperoleh adalah sebagai berikut:

1. Para pengelola atau penerima hibah buku dapat memahami pengetahuan dasar dalam pengolahan koleksi monograf dengan mengunakan sistem otomasi perpustakaan.

2. Koleksi yang diberikan sudah dapat digunakan/dilayankan langsung kepada para pengguna taman bacaan masyarakat karena koleksi ini terlebih dahulu sudah diolah dan dientrie ke dalam sistem yang telah dirancang unutk pengelolaan perpsutakaan dan taman bacaan masyarakat.

3. Menstimuli

untuk pendirian/perintisan perpustakaan desa, perpustakaan sekolah, dan taman bacaan masyarakat di sekitar para penerima hibah buku untuk bergerak merintis pendirian taman baca, sehingga akan semakin mudah untuk mewujudkan masyarakat informasi (information society).

\section{Kesimpulan}

Kegiatan Hibah buku mahasiswa angkatan 2013-2014 telah tersampaikan ke berbagai jenis perpustakaan dan taman bacaan baik itu perpustakaan sekolah, taman bacaan masyarakat dan perpustakaan Lapas. Diberikan kepada sekolah yang belum memiliki perpustakaan dan sekolah yang belum memenuhi standar jumlah koleksi. Taman bacaan yang mendapat hibah adalah taman bacaan yang memulai dan mengembangkan dengan motivasi yang kuat dari pengelolanya.

Dengan demikian, permasalahan yang menjadi alasan klasik dalam pengelolaan perpustakaan yaitu pengelolaan koleksi sudah dapat diselesaikan dengan cara mengadakan pelatihan pengelolaan bahan pustaka dengan sistem otomasi perpustakaan. Koleksi yang sudah diolah dan dientri kepada sistem dapat membantu mitra kegiatan untuk langsung melayankan koleksi tersebut kepada para anggota.

Kegiatan ini selanjutnya akan berlanjut pada pembinaaan mitra oleh Departemen Ilmu Informasi dan Perpustakaan. Perpustakaan dan Tamaan Bacaan Mitra akan dijadikan sebagai laboratorium riset yang dikembangkan untuk perpustakaan sekolah, perpustakaan Lembaga Pemasayarakatan dan taman bacaan masyarakat.

\section{Daftar Pustaka}

Ainan, Denny S. 2013. Orang Indonesia Tidak Suka Membaca. MetroTv.Com. Retrieved 21 Desember 2013, pukul 23.00 WIB from:

http://www.metrotvnews.com/met ronews/read/2013/10/01/3/185344 
/Orang-Indonesia-tidak-SukaMembaca .

Lembaga Penelitian dan Pengabdian Kepada Masyarakat. 2013. Panduan Penulisan Proposal Program Hibah Pengabdian Kepada Masyarakat Universitas Padjadjaran 2013. Jatinangor : UNPAD

Nahaba, Budi. UNESCO Beri Indonesia Penghargaan Terkait Program Buta Aksara; Indonesia mendapat penghargaan dari UNESCO atas keberhasilan program mengurangi buta aksara. Voice of America. Retrieved 18 Desember 2013, Pukul 18.00 WIb Form:

http://www.voaindonesia.com/con tent/unesco-beri-indonesiapenghargaan-terkait-programbuta-aksara/1494826.html

Ucu, Karta Raharja. 2013. Kemendikbud: 3,6 Juta Rakyat Indonesia Buta Huruf. Republika Online. Retrieved 20 Desember 2013, pukul 20.00 from: http://www.republika.co.id/berita/ nasional/umum/13/11/28/mwyw5l -kemendikbud-36-juta-rakyatindonesia-buta-huruf

Peraturan Menteri Pendidikan Nasional RI No. 25 Tahun 2008 Tentang Tenaga Kependidikan. Jakarta : Kemendiknas RI.

Sutarno NS. 2004. Manajemen Perpustakaan Sekolah. Jakarta : Samitra Media Utama
Undang-Undang No. 43 Tahun 2007 Tentang Perpustakaan. Jakarta : Perpustakaan Nasional RI.

Unpad. 2010. “Unpad Sumbangkan Buku ke Yayasan Al Yahya dan Pemkab Tasikmalaya”. Diakses 27 September $2013 \quad$ di http://news.unpad.ac.id/?p=15275.

Unpad. 2012. "Rencana Induk Penelitian 2012-2016”. Diakses 27 September $2013 \quad$ di http://www.lppm.unpad.ac.id/wpcontent/uploads/2012/02/RIPUnpad2012.pdf

Eryono, Muh. Kaliani. 1993. Pengolhan Bahan Pustaka. Jakarta: Universitas Terbuka

Sumantri, M.T.2006. Panduan Penyelenggaraan Perpustakaan Sekolah. Bandung: Rosda

Sumardji, P. 1984. Mengelola Perpustakaan: Tata kerja Pengolahan, Penyimpanan dan Penyusunan Buku dengan Kartukartu Katalog di Perpustakaan. Yogyakarta: Kanisiuss

Sumarno. $\quad 1983 . \quad$ Pembimbing Perpustakaan Sekolah. Jakarta: Akadoma

Sjahrial-Pamuntjak, Rusina. 2000. Pedoman Penyelenggaraan Perpustakaan. Jakarta: Djambatan 